Marina Romagnoli Bethonico ${ }^{1}$

\title{
Fazer mundos, fabricar possíveis: Práticas do artista do fingere
}

Making worlds, manufacturing possibles: practices of the fingere artist

Faire des mondes, fabriquer des possibles: Des pratiques de l'artiste du fingere 


\title{
Resumo
}

Este texto tem como objetivo discorrer sobre as motivações que me ligam à pesquisa teórica e prática em artes visuais que tenham implicações coletivas. Após uma breve introdução ao meu percurso de artista-pesquisadora, uma contextualização das disciplinas teóricas com as quais me envolvo é apresentada a fim de iniciar uma reflexão acerca da imagem fotográfica, no contexto da arte contemporânea, e sua produção de instantes, alinhada a um tempo aiônico coerente com sua lógica de manipulação. A teoria dos mundos possíveis visuais norteia essa reflexão, na qual as noções de "fingere" e de "imagem-ficção" se destacam. Um estudo de caso é apresentado, a partir do trabalho do artista Éric Baudelaire, que articula ambiguidades da imagem para pensar as potências do falso na re-construção de outras versões da dita realidade. Conclui-se que a imagem (pós-)fotográfica contemporânea transita entre três graus: o evento original, o histórico e o de imagem. Esse último se vale da potência modificadora de mundos, que a imagem-ficção porta consigo, para estimular o movimento na direção e na criação de novos caminhos coletivos.

Palavras-chave: mundos possíveis; fingere; imagem-ficção; fotografia; Éric Baudelaire.

\begin{abstract}
The paper aims to discuss the motivations connecting me to theoretical and practical research in visual arts that have collective implications. After a brief introduction to my career as an artist-researcher, a contextualization of the theoretical disciplines with which I am involved is presented in order to begin a reflection about the photographic image, in the context of contemporary art, and its production of instants, aligned with an ionic time coherent with its logic of manipulation. The theory of visual possible worlds guides this reflection, in which the notions of "fingere" and "image-fiction" stand out. A case study is presented, based on the work of the artist Éric Baudelaire, who articulates image's ambiguities in order to reflect on the powers of the false in the re-construction of other versions of the so-called reality. It is concluded that the contemporary (post-)photographic image transits between three degrees: the original event, the historical event and the image event. The latter uses the power of modifying worlds, which the image-fiction carries with it, to stimulate the movement in the direction and the creation of new collective paths.
\end{abstract}

Key-words: possible worlds; fingere; image-fiction; photography; Éric Baudelaire.

\section{Resumé}

Ce texte a pour but de discuter les motivations qui me lient à la recherche théorique et pratique en arts visuels qui ont des implications collectives. Après une brève introduction à mon parcours d'artiste-chercheuse, une présentation des disciplines théoriques auxquelles je m'engage est menée afin d'entamer une réflexion sur l'image photographique, dans le contexte de l'art contemporain, et sa production d'instants, alignée à un temps aiônique cohérent avec sa logique de manipulation. La théorie des mondes possibles visuels guide cette réflexion, dans laquelle les notions de « fingere » et d'« image-fiction » ressortent. Une étude de cas est présentée, à partir du travail de l'artiste Éric Baudelaire, qui articule les ambiguïtés de l'image afin de réfléchir aux puissances du faux dans la reconstruction d'autres versions de ladite réalité. On en conclut que l'image (post-)photographique contemporaine transite entre trois degrés : l'événement original, celui historique et celui d'image. Ce dernier utilise la puissance modificatrice de mondes, que l'image porte en elle, pour stimuler le mouvement vers la création de nouvelles voies collectives.

Mots clés: mondes possibles ; fingere ; image-fiction ; photographie ; Éric Baudelaire.

${ }^{1}$ Marina RB é artista e pesquisadora, doutora pela Université Sorbonne-Nouvelle Paris 3 (2019/DPE-CAPES), mestre e bacharel pela Escola de Belas Artes da UFMG (2015 e 2011). LATTES: http://lattes.cnpq.br/1234164803125109 / ORCID iD: https://orcid.org/0000-0002-4981-3403 / marinarb@gmail.com 


\title{
1. INTRODUÇÃO
}

\begin{abstract}
Vous voyez, monsieur Nicetas, dit Baudolino : quand je n'étais pas en proie aux tentations de ce monde, je passais mes nuits à imaginer d'autres mondes. [...] Il n'y a rien de tel qu'imaginer d'autres mondes pour oublier à quel point le monde dans lequel nous vivons est douloureux. C'est du moins ainsi que je pensais alors. Je n'avais pas encore compris qu'imaginant d'autres mondes, on finissait aussi par changer celui-ci.

U. ECO
\end{abstract}

A capacidade de produzir e de dar a ver mundos é das faculdades que as artes visuais possuem que mais me atrai à esse campo. Enquanto artista e pesquisadora, fui descobrindo essa faceta aos poucos, no percurso de minha formação, no próprio desenvolver de minhas produções imagéticas e teóricas que, hoje, posso retraçar para perceber o que me motiva a prosseguir pesquisando. Imaginar, articular e imagear mundos, situações, versões do real, de pessoas, paisagens... manipulando materiais, textos, ideias. Práticas do artista do fingere.

Exponho aqui brevemente esse percurso, a fim de contextualizar o que virá mais adiante. Quando cursei Artes Visuais², fui aos poucos descobrindo uma prática artística alinhada com uma formulação da arte enquanto criadora de mundos diferentes, articulando a ficção em imagem sem precisar lançar mão de recursos narrativos lineares. Nessa época, estava interessada nas fronteiras movediças da ficção e dos fatos na fabricação daquilo que chamamos de realidade - o que culminou, ao final do curso, em uma série de gravuras em metal apresentada como um tratado de arquitetura fictício (Fig. 1 e 2).

A questão era: a ficção pode se dar em imagem? Descobri que sim: posso manipular informações e imagens, para dar a ver um resultado híbrido entre os fatos e as ficções; apresentar uma construção que à primeira vista poderia parecer bastante figurativa e verídica, mas que, com um olhar atento, desvelaria suas pequenas facetas fictícias. Isso não com o objetivo de confundir, mas a fim de enriquecer os imaginários e concepções da realidade que podemos ter e propagar. 


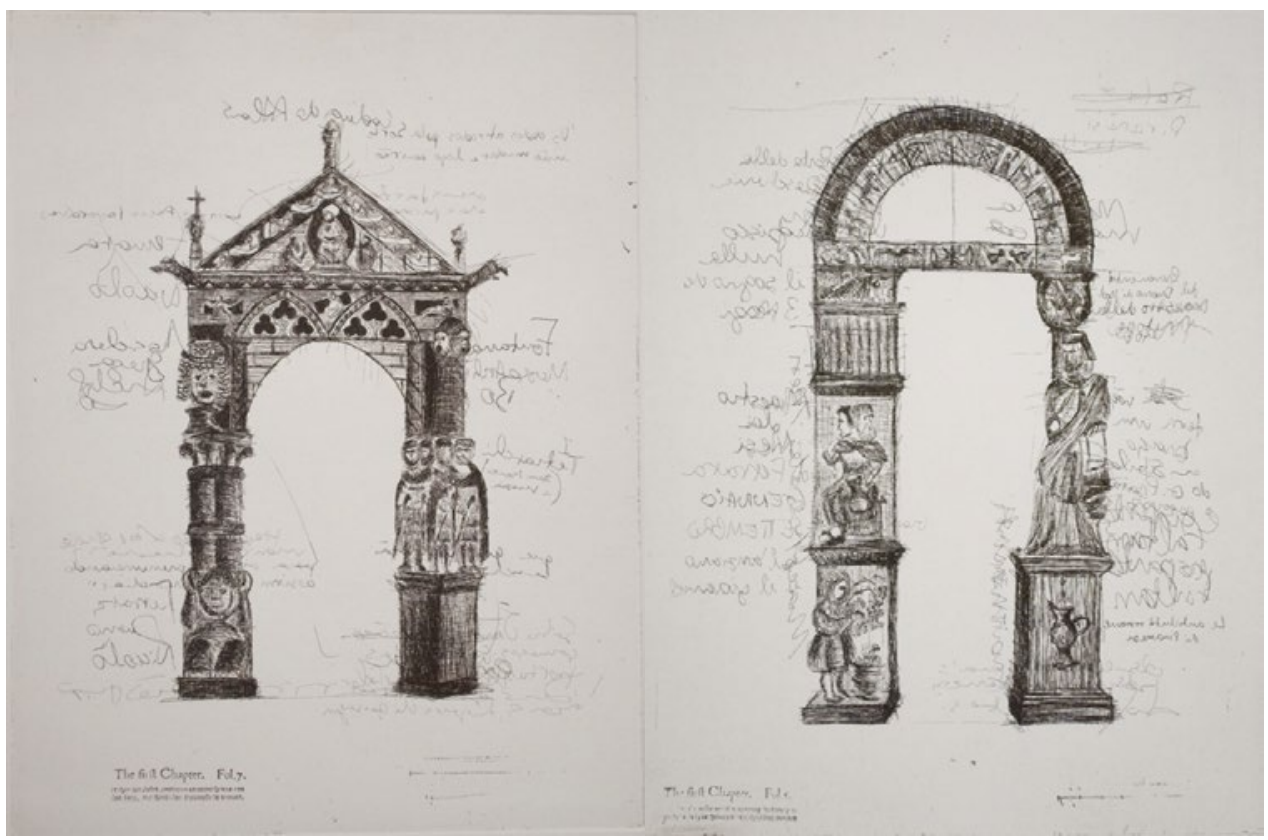

Fig.1 e 2: Marina RB, I tetrarchi e Maestro dei Mesi (série Architettura), 2010. Gravura em metal, 35x26 cm. Fonte: www.marinarb.com/trabalhos/item/18-architettura

Tais constatações, ainda em estado embrionário, culminaram em uma pesquisa de mestrado. A dissertação "artista que fingere: a manipulação da imagem entre a imanência, as sobrevivências e a dupla-dobra" (BETHONICO, 2015), orientada pela

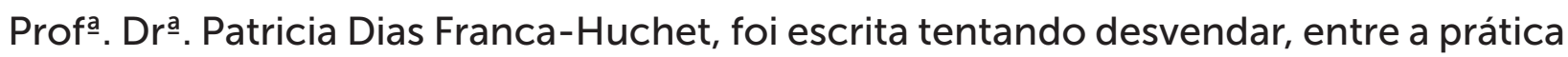
e a teoria, o lugar de quem está por trás dessas criações híbridas. Muito investiguei sobre os métodos de pesquisa capazes de combinar teoria e prática nas artes visuais, encontrando na fórmula "fazer o fazer, pensar sobre o fazer, pensar sobre o pensar, fazer o pensar" uma aliada desse exercício. Entender o artista como praticante do fingere, isto é, como um manipulador de materiais, imagens e conceitos para produzir realidades, no plural, foi essencial para prosseguir meu caminho em busca da ficção em imagem.

Como se na graduação tivesse descoberto o "quê" me interessava na arte e, no mestrado, "quem" era capaz de produzi-lo, no doutorado pude ir em busca do "como". A curiosidade em torno das possibilidades de concretização de outros mundos possíveis através da imagem artística sustentou meu desejo de realizar a pesquisa, que, ao fim, intitulou-se "IMAGE-FICTION, IMAGE-ACTION. Mise en jeu de la photographie contemporaine entre théorie des mondes possibles et théorie des actes d'image" (BETHONICO, 2019), orientada pelo Prof. Dr. Philippe Dubois. Minha hipótese era, grosso modo, que certas imagens artísticas teriam uma força de criação e propagação de mundos contida nelas mesmas, apresentando variadas versões desses mundos e expondo seu caráter manipulado, instaurado pelo fingere do artista. Essas imagens, por não esconderem o fato de serem manipuladas, permitiriam ao espectador encontrar pistas da construção forjada de mundo que elas veiculam. Isso a fim de conhecer e entender vias que levam da ficção para a uma espécie de ação livre, com efeitos no mundo dos fenômenos, como se a imagem fizesse um convite para a construção de novos contextos. Em outras palavras, seria como um funcionamento espiralado de um feitio da imagem que geraria ele mesmo: o que ela tem como traço 
da manipulação que a originou, é o que ela vai multiplicar no espaço onde é recebida - como uma semente lançada, uma forma embrionária e viva de multiplicação. Pesquisei essas maneiras de fazer mundos tendo como objetos imagens fotográficas.

Reconheço que essa hipótese é um tanto quanto otimista em relação ao papel da arte no mundo atual. De todo modo, ela me habitou com tamanha força e presença, que me impulsionou ao movimento de conclusão daquela pesquisa. Através dela, eu sentia o motivo por ter me envolvido com imagens e por estar atuando nessa área, até hoje. Essa hipótese atravessou todo o período do doutorado a meu lado, fez parte do meu amadurecimento enquanto pesquisadora e foi uma companheira nesse percurso tão solitário que é a escrita de uma tese. De certa forma, era ela a minha convicção, de que era preciso escrever e de que valeria à pena chegar até o fim; era ela o que eu queria dizer, provar, o que me movia. Foi ela que me fez descobrir a singularidade de minha pesquisa.

É importante retraçar esse contexto pois é ele que me trouxe até aqui, neste momento, escrevendo este texto. Esse percurso carrega o que me motiva a insistir na arte enquanto potência modificadora do mundo vivido. Além disso, é nesse percurso que vejo lançadas as noções que sustentam meu pensamento-prática em artes visuais, que despertam o meu desejo e que me fazem seguir trabalhando e produzindo nessa área do conhecimento.

\section{FAZER MUNDOS ATRAVÉS DA FOTOGRAFIA}

É evidente que, nesse encontro com a arte, existem elementos que compõem o meu interesse na disciplina que extrapolam o percurso pessoal e que tocam as esferas de sua teoria e história. Assim, considero importante localizar minha pesquisa mais recente em um contexto específico, que circula em torno das teorias da fotografia e que propõe uma outra via para se pensar a imagem fotográfica, sem deixar de reverberar num estudo mais abrangente da imagem.

Considerando o percurso histórico dessas teorias, durante os anos 80, a fotografia conheceu uma legitimação teórica a partir de obras que consolidam, segundo Philippe Dubois (2016, não paginado, tradução nossa), três categorias:

[...] primeiro de tudo a ideia de um "noema" da fotografia (termo usado por Roland Barthes para propor uma essência do meio), que caberia inteiramente dentro da fórmula do "ça a été". Então, e sobretudo (porque seu uso foi maciço - mesmo que sem domínio - por mais de dez anos), o conceito de index (ou índice - por distinção ao ícone e ao símbolo), uma noção emprestada do semiótico estadunidense Charles Sanders Peirce, que foi sucessivamente convocada por Dubois, Van Lier, Schaeffer, Brunet. E, finalmente, no final da década, esse movimento levou à promoção desta famosa noção de "Fotográfico" (este é o título do livro de Rosalind Krauss que encerra os anos 80) como uma categoria em si e por $\mathrm{si}^{3}$. 
Após uma década não tão fértil em estudos teóricos sobre fotografia, a partir dos anos 2000, Dubois (2016) observa um ressurgimento de trabalhos importantes sobre o assunto na França (BAQUÉ, 2004; CHÉROUX, 2003; GUNTHERT, 2007; POIVERT, 2002, 2007; ROUILLÉ, 2005). Vê-se então uma mudança de perspectiva: "À pergunta 'o que é a fotografia?' segue-se esta outra pergunta fundamental: 'o que a fotografia pode fazer?' (qual é seu propósito? quais são os valores que ela transmite e que nós lhe atribuímos?)." (DUBOIS, 2016, não paginado, tradução nossa) ${ }^{4}$. Investimentos históricos, estéticos, pragmáticos e orientados para a cultura visual marcam esses textos, abrindo caminho para estudos menos focados na ontologia e no dispositivo fotográficos, como havia acontecido nos anos 80.

A partir desse momento, a crescente popularização da Internet e as revoluções digitais mudaram efetivamente nossa relação com todas as imagens (GUNTHERT, 2015). No caso da fotografia, esses dois eventos provocaram transformações não apenas em relação à natureza da imagem (agora digital), mas também na forma como são produzidas (agora também por máquinas autônomas) e difundidas. Atualmente, a fotografia ocupa uma posição de destaque em nossa relação com o mundo e com as outras pessoas. Não digo isso apenas pelo fato do digital ter tornado banal a manipulação da imagem - sabemos bem que a manipulação da imagem fotográfica acontece desde o seu surgimento, no século XIX (o que é visível na produção de Hippolyte Bayard, Oscar Rejlander, Valério Vieira, ou mesmo na produção amadora, para citar alguns poucos exemplos) $)^{5}$. A questão que coloco é que a produção, a circulação e o funcionamento das imagens fotográficas no mundo contemporâneo exigem e mostram outros caminhos teóricos para abordar essas imagens, mais centrados no que elas apresentam - e não representam, mesmo que ficcionalmente -, no que elas produzem como real - e não reproduzem -, nas transformações que realizam a partir de um mundo dito de referência ${ }^{6}$ - que pode ou não ser o mundo real. Ou seja, não se trata de uma questão apenas de conteúdo - fictício ou não -, de manipulação (ou não) ou de categorização - fotografia artística ou não. O contexto contemporâneo é mais complexo justamente por confundir categorias, sendo que lidamos cada vez mais com imagens fotográficas que são, de certa forma, ontologicamente fictícias (DUBOIS, 2016) - como é caso das imagens GAN, que veremos mais à frente: imagens compostas geradas por máquinas a partir de uma infinidade de referências visuais não rastreáveis, diferentemente das imagens compostas da fotografia analógica (como as de Francis Galton, para dar um exemplo no campo da fisiognomia, que dialoga com o contexto das GAN de rostos humanos).

Em minha tese de doutorado, trabalhei dois regimes contemporâneos de funcionamento das imagens fotográficas que parecem trabalhar juntos: a imagem-ação e a imagem-ficção - abrangendo imagens artísticas, mas também fotojornalísticas,

\footnotetext{
4 'À la question 'qu'est-ce que la photographie ?' succède ainsi cette autre question de fond : 'que peut la photographie ?' (à quoi sert-elle ? quelles sont les valeurs qu'elle véhicule et qu'on lui attribue ?)." (DUBOIS, 2016, não paginado).

5 Ver: Gunther \& Poivert (2007) e Fineman (2012), dentre inúmeros títulos que abordaram esse assunto. Essa questão também foi longamente explorada em minha tese de doutorado (BETHONICO, 2019), que conta com uma extensa bibliografia específica na área.

$6 \quad$ Um mundo é dito "de referência" quando uma obra se refere a ele, através de enunciados ou imagens, sendo possível fazer referência a um ou mais mundos (real ou ficcionais). Independente das diferentes concepções de "mundos possíveis" que possa se ter, "[...] elas permitem enxergar os mundos de ficção como mundos de referência, a partir dos quais pode-se acessar múltiplos mundos possíveis." (LAVOCAT, 2016, p. 387, tradução nossa).
} 
memes da Internet, entre outras. Essa dinâmica se dá, por um lado, em imagens que insistem em dar uma única versão do chamado mundo real, ou de eventos políticos e históricos; imagens que são manipuladas, mas que escondem esse caráter, querendo apresentar-se como verdade; imagens que certamente encontram uma agentividade, mas que visam fechar os horizontes do pensamento do receptor em um longo loop de reação, bem como limitar a diversidade da produção de diferentes realidades ou versões. É o caso da imagem-ação.

Por outro lado, vemos imagens que também são manipuladas, mas que se auto-denunciam como tal, que não escondem esse caráter; imagens que abrem possibilidades, que as constroem e as expõem; imagens que são ativas e que geram ações-livres, que querem contribuir para o pensamento e para a criação de um mundo atual mais plural - é o caso da imagem-ficção. Embora essa diferença possa parecer maniqueísta, ela expõe duas lógicas distintas - entre diversas outras - de enfrentar o mundo vivido, que partilham fronteiras movediças entre diferentes usos das imagens, seja com fins de dominação, seja com fins de aprendizados e questionamentos diversos.

A teoria que propus, intitulada teoria dos mundos possíveis visuais, acompanha a agentividade e o trajeto da ficção em imagem - presente na história da fotografia desde os seus primórdios. Ela não pretende substituir qualquer teoria já existente, mas somar a esse campo de estudo mais uma alternativa para se pensar a imagem fotográfica manipulada - seja por pessoas ou, como acontece cada vez mais desde o surgimento das tecnologias digitais, por máquinas. Se, como escreve Hans Belting (2007, p. 46, tradução nossa), "O mundo não é mais [...] a matriz das imagens, mas são elas que se tornaram as matrizes do mundo"7, vemos um contexto no qual a dita realidade não é mais a origem por excelência das imagens, pois as imagens se fizeram elas também origens. É o caso, por exemplo, das imagens GAN (Generative Adversarial Networks): imagens (pós-)fotográficas que não são fruto de uma captura direta do mundo dos fenômenos - a partir de uma câmera física que capta uma imagem do espaço que entendemos por real -, mas que ganham forma através da imagem fotográfica composta, gerada por máquinas. Para ver um exemplo disso, basta visitar um site criado para conscientizar o público leigo dessa tecnologia, intitulado "esta pessoa não existe" (www.thispersondoesnotexist.com). Cada vez que o site é atualizado, a rede gera uma nova face (Fig. 3 e 4). Esses rostos, inexistentes no mundo dos fenômenos, nos parecem familiares, mas são frutos de uma combinação complexa de várias imagens fotográficas armazenadas em bancos de dados e que seguem um padrão extremamente ocidental.

7 "Le monde n'est plus [...] la matrice des images, mais ce sont elles qui sont devenues les matrices du monde." (BELTING, 2007, p.46). 


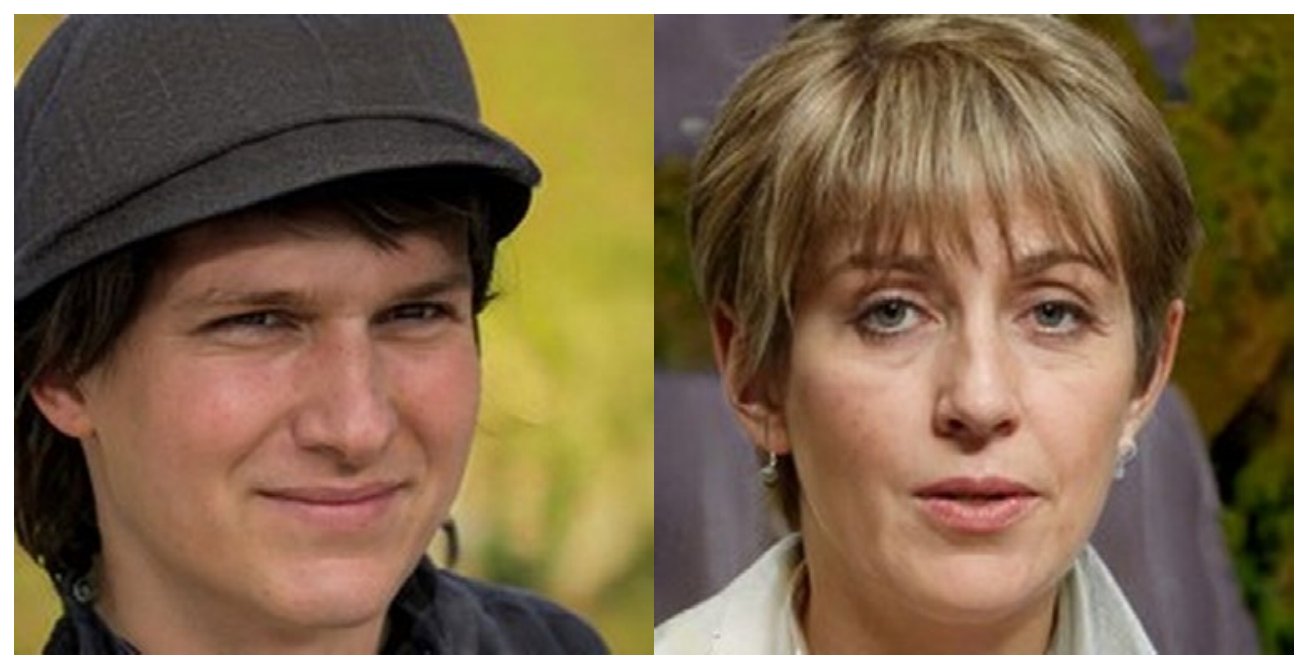

Fig. 3 e 4: Exemplos de imagens GAN, 2020. Fonte: www.thispersondoesnotexist.com

A necessidade de estabelecer novos caminhos para abordar a imagem fotográfica é evidente, uma vez que essas imagens não apenas podem representar uma ficção, mas se apresentar como tal. Nesse sentido, a via da teoria dos mundos possíveis visuais não se baseia na ontologia da imagem-traço, mas, justamente, nas imagens que são evidentemente produzidas, manipuladas, gerando um efeito de imagem-traço. Se as imagens-traço se conectam a um passado por tê-lo "capturado", as imagens-ficção fabricam momentos, por apresentarem situações contrafactuais de seus mundos de referência ${ }^{8}$. Em outras palavras, se o que uma imagem-ficção dá a ver não existiu nem aconteceu na atualidade do mundo que habitamos, se ela é fruto de uma manipulação imagética e conceitual, o que ela exibe se conecta a um tempo específico, produzido por práticas do fingere. Esse tempo não é localizável de forma pontual, e por mais que um trabalho possa fazer referência a um evento específico, isso está inscrito em sua natureza: a imagem não provém diretamente do real.

Refletindo teoricamente, vejo essa produção de instantes alinhada com um tempo aiônico, e não cronológico, segundo a distinção que coloca o filósofo Gilles Deleuze (1969, p. 194, tradução nossa): “Enquanto Chronos era limitado e infinito, Aiôn é ilimitado como o futuro e o passado, mas finito como o instante" 9 . Para Deleuze (1969, p.190, tradução nossa), de acordo com a leitura do tempo de Chronos, “[...] só o presente existe no tempo. Passado, presente e futuro não são três dimensões do tempo; apenas o presente preenche o tempo, o passado e o futuro são duas dimensões relativas ao presente no tempo"10. Diferentemente, segundo Aiôn, é o passado e o futuro que subsistem no tempo: "Em vez de um presente que reabsorve o passado e o futuro, um futuro e um passado que dividem a cada instante o presente, que o subdividem infinitamente em passado e futuro, em ambas as direcções ao mesmo

8 A noção de "contrafactualidade" define, no campo da lógica modal, as relações de reflexão sobre os eventos que não se realizaram mas que poderiam ter se realizado sob certas condições.

9 “Alors que Chronos était limité et infini, Aiôn est illimité comme le futur et le passé, mais fini comme l'instant."(DELEUZE, 1969, p.194).

10 "[... seul le présent existe dans le temps. Passé, présent et futur ne sont pas trois dimensions du temps; seul le présent remplit le temps, le passé et le futur sont deux dimensions relatives au présent dans le temps."(DELEUZE, 1969, p.190). 
tempo" (DELEUZE, 1969, p.194-195, tradução nossa)11. As imagens-ficção não se alinham com uma lógica de tempo linear e contínua, mas escaneiam os espectros do passado e do futuro em busca de suas formas e de sua produção de instantes.

Assim, de acordo com a lógica temporal cronológica, a ideia da fotografia tradicional é estruturada capturando o instante do tempo presente, um instante perdido e paralisado pela imagem fotográfica - o que diz de uma concepção de presente cronológico tradicional que se impõe prioritário frente a um passado e um futuro distantes e intocáveis. De uma forma diferente, o tempo aiônico pressupõe um presente sempre intocável, fugaz, comprimido por um passado e um futuro que caminham juntos. Nessa direção, vejo a fotografia permitindo a articulação do passado e do futuro na produção de presentes, causando movimentos de ida e volta no tempo histórico, para fabricar instantes a fim de produzir mundos outros, estabelecendo diferentes paradigmas para o tempo e para o mundo dos fenômenos - seja em imagens do século XIX ou atuais.

É irrefutável que a História, enquanto disciplina, pode impor-se linear. No entanto, certos artistas têm abordado o tempo e as matérias histórica e real de maneiras bem mais flexíveis. $O$ discurso histórico tem um peso, isso é evidente, mas é inegável que certas imagens atravessam os tempos, que elas sobrevivem e permanecem vivas: imagens em movimento no tempo aiônico. Imagens que, mesmo históricas, não são intocáveis, assim como a história não é considerada intangível por artistas que adotam uma nova relação com o passado e com o futuro, revelando uma concepção diferente do tempo, que sucede a visão progressista do século XX artístico. Pensar o tempo da imagem coerente com a sua lógica de manipulação é uma tarefa útil para os domínios teóricos da arte. Afinal de contas, é preciso manipular para produzir mundos e versões de mundos, assim como para produzir pensamento sobre a imagem. Como diria Georges Didi-Huberman (2002, p. 136, tradução nossa), "Não se produz um conhecimento sobre as imagens sem as manipular."12

\section{FABRICAR A HISTÓRIA: UM ESTUDO DE CASO}

Em notas escritas para a curadoria de uma exposição imaginária intitulada Factographies, o artista franco-estadunidense Éric Baudelaire discute os poderes e potências das imagens, bem como a sua capacidade de transitar através de tempos heterogêneos. Baudelaire (2018, p. 247) escreve:

Se o século XX é aquele da imagem, suas horas mais sombrias são demarcadas pelas lacunas de representação. Há poucas fotografias no museu de $\mathrm{Hi}-$ roshima porque não há imagem "suficiente" para dizer Hiroshima. [...] Não há então, não pôde haver, imagens do acontecimento atômico. E se houvessem, elas seriam suficientes?

Em um debate que trata da dialéctica existente entre as imagens da história

11 "Au lieu d'un présent qui résorbe le passé et le futur, un futur et un passé qui divisent à chaque instant le présent, qui le subdivisent à l'infini en passé et futur, dans les deux sens à la fois." (DELEUZE, 1969, p.194-195).

12 "On ne produit pas un savoir sur les images sans les manipuler." (DIDI-HUBERMAN, 2002, p.136). 
humana e do mundo vivido e as imagens ausentes de acontecimentos passados, Baudelaire nota a existência de uma polaridade que parece dividir o comportamento das pessoas frente a essas imagens: por um lado, os iconoclastas, que não querem olhar para nenhuma imagem, que podem mesmo destruí-la para não visualizar um passado trágico; por outro, os iconófilos, salvando imagens existentes que dizem a história para colocá-las em evidência. Como uma consequência contemporânea dessa oposição, Baudelaire detecta uma terceira via aberta por essa dialéctica, na qual ele, enquanto artista, se inscreve:

[...] frente à natureza lacunar das imagens, fabriquemos imagens! Fabriquemos um excesso de imagens, uma barragem de imagens, uma sobredose de imagens. Mais que isso, pelo dispositivo do falso documentário, elevemos essas imagens ao estatuto de símile-documento. (BAUDELAIRE, 2018, p. 248).

Éric Baudelaire é um artista do fingere. Ele faz história, ele fabrica imagens-ficção evidentemente manipuladas; ele procura traços da construção das realidades, ele busca produzir mundos através de "[...] práticas artísticas tornando absolutamente solidários documento e ficção, cada um atenuando a insuficiência do outro." (BAUDELAIRE, 2018, p. 250). Baudelaire é um fabricante de terceiras versões de eventos, de terceiros graus da história - entendendo esses três graus como: o evento histórico no momento em que ele acontece; as imagens oficiais desse evento; a re-elaboração destes últimos para construir uma nova versão. Re-elaboração essa que gera, segundo nossa teoria, imagens-ficção que carregam traços das maneiras de fazer mundos, das maneiras de produzir realidades diferentes, em novas combinações.

Basta olhar para a célebre imagem do artista: The Dreadful Details (2006), apresentada pela primeira vez no festival de fotojornalismo Visa pour l'image (Fig. 5). A imagem apresenta uma cena de guerra em Bagdá que, observando bem, organiza de uma só vez todos os clichês da imagem fotojornalística de guerra: a mãe desesperada, a criança ferida, o idoso amedrontado... Visivelmente, Baudelaire joga com os códigos do fotojornalismo tradicional de guerra para denunciar sua estetização no mercado de arte.

O cenário de Baudelaire se apresenta em parte como uma cópia de uma série de televisão estadunidense sobre a guerra no Iraque (GRENIER, 2014). Esse detalhe constitui uma pista que evidencia o caráter produzido da imagem supostamente fotojornalística do artista que deveria, em tese, ilustrar a guerra de maneira crua sem nenhum retoque, representando a verdade da guerra. Sobre o seu trabalho, Baudelaire (2017, não paginado, tradução nossa) comenta que

The Dreadful Details é um projeto fotográfico bastante discursivo. Ele tenta agrupar inúmeras questões da história da arte em uma imagem que trata da guerra e de sua representação. À princípio, tratava-se de uma encomenda do Ministério da cultura francês. Eu imagino que eles esperavam que eu fosse no Iraque ou em alguma outra zona de conflito para fazer paisagens com uma câmera de grande formato. Ao invés disso, fui a Los Angeles em um pequeno rancho que havia sido convertido em set de filmagens. Tinha um "vilarejo mexicano" transformado em "vilarejo afegano" depois do 11 de setembro. Em 2006, quando comecei a trabalhar em The Dreadful Details, tratava-se de um "vilarejo iraquiano" totalmente construído por um carpinteiro de 25 anos 
que nunca havia saído dos Estados Unidos e que baseou suas construções em imagens da revista Time. Eu usei o dinheiro da comissão para contratar pessoas que haviam trabalhado em um set de televisão hollywoodiano no Iraque, bem como atores e figurantes que normalmente encenavam árabes (mesmo que a maior parte deles não fossem árabes), antigos fuzileiros que trabalhavam como consultores para a televisão, pessoas para os figurinos e maquiagens, e assim por diante. E tentei compor com eles uma imagem de guerra na tradição das pinturas da história, como aquelas com as quais eu cresci visitando no Louvre, realizadas por artistas como Géricault, Delacroix e Manet ${ }^{13}$.
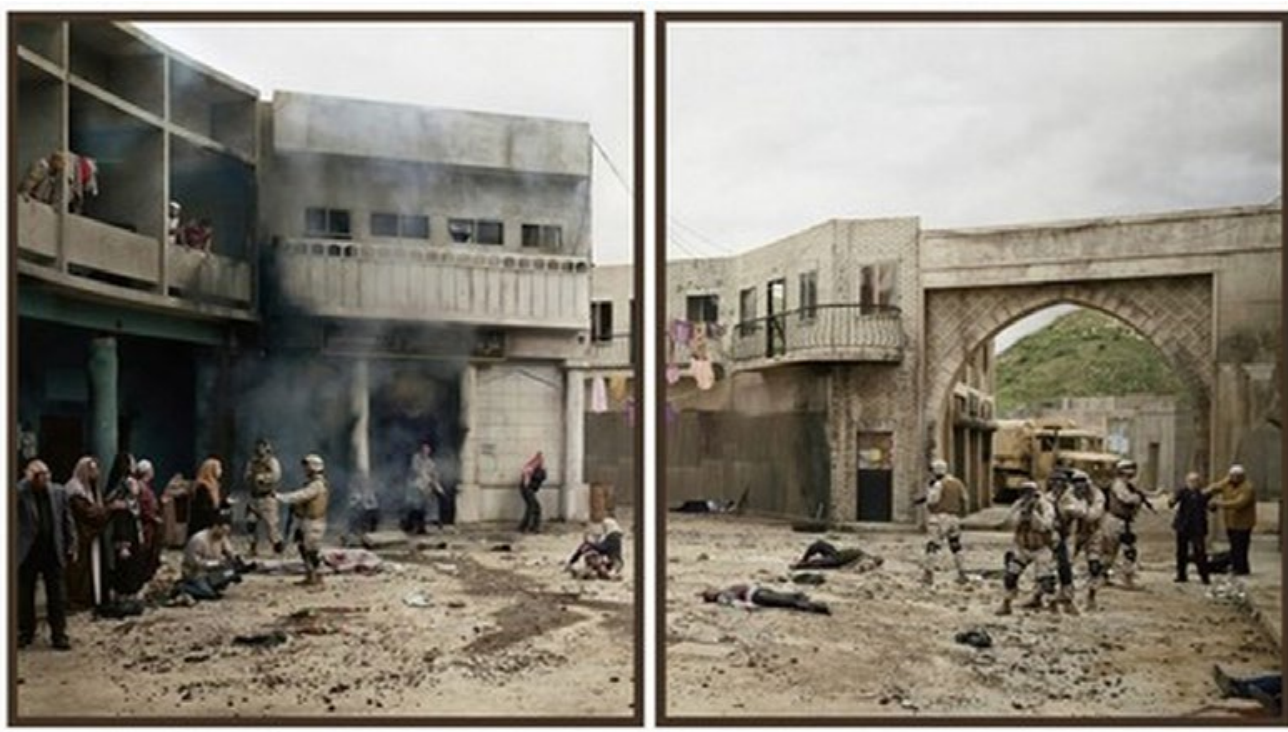

Fig.5: Éric Baudelaire, The Dreadful Details, 2006. C-print, 209 x 375 cm. Fonte: www.baudelaire.net/circum/the-dreadful-details/

O artista joga, com sua imagem-ficção, o mesmo jogo da imagem fotojornalística, para denunciar e fazer pensar sobre a construção da representação da guerra 14. Mas como ele joga esse mesmo jogo? Apresentando uma imagem evidentemente produzida - de forma que fica claro sua semelhança com imagens oficiais de guerra, seja do presente ou do passado - e apresentando os clichês que esperamos dessas imagens - uma vez que nós temos, sim, expectativas com as imagens. $O$ trabalho de Baudelaire, claramente produzido, joga com a manipulação da imagem e convida a uma reflexão sobre a representação da "verdade" em si, tão cara ao campo da fotorreportagem, que abomina e julga qualquer manipulação. Como bem observa o crítico de arte Régis Durand (2009, p. 32, tradução nossa), "O fato de uma observação atenta permitir notar que se trata de uma mise-en-scène faz com que esse trabalho

\footnotetext{
13 "The Dreadful Details is a very discursive photographic project. It tries to pack a lot of art-historical questions into an image that deals with war and its representation. Initially it was a commission from the French Ministry of Culture. I think they expected me to go to Iraq or another conflict zone to do landscapes with a large-format camera. Instead, I went to Los Angeles to a small ranch that had been converted into film sets. There was a "Mexican village" that had been converted into an 'Afghan village' after 9/11. By 2006, when I started to work on The Dreadful Details, it was an 'Iraqi village' built entirely by a twenty-five-year-old carpenter who had never left the United States, and who had based his constructions on pictures from Time magazine. I used the money from the commission to hire people who worked on a Hollywood TV series set in Iraq, actors and extras who frequently played Arabs (although most of them weren't Arab), former Marines who worked as TV consultants, costume and makeup people, and so on. And I tried to compose a war image with them in the tradition of history paintings like the ones I grew up seeing in the Louvre by artists like Géricault, Delacroix, and Manet. The result was a picture, or rather two, because it's a diptych, but the process was very cinematic, and it made me want to make films." (BAUDELAIRE, 2017, não paginado).
}

14 Sobre o uso de encenações por autoridades no preparo de exércitos para a guerra, ver: <https://cisac.fsi.stanford.edu/multimedia/through_explosions_ and_gunfire_stanford_scholars_see_troops_train_for_afghanistan_combat_20120430>. Ver também o trabalho de Harun Farocki à respeito (Serious Games I-IV, 2009/2010): <https://www.harunfarocki.de/installations/2010s.html>. Acessos em: 14 dez. 2020. 
seja visto como uma ficção crítica, embora às custas de uma certa ambiguidade."15

Se considerarmos que diferentes valores de verdade podem ser fabricados através de imagens, o falso não participa de uma oposição radical contra essa categoria, já que uma imagem não é ou verdadeira ou falsa. A teoria dos mundos possíveis visuais permite sustentar esses diferentes valores, desde que eles façam referência a diferentes mundos. Vejamos: as teorias dos mundos possíveis são oriundas do campo da lógica modal, que é um sistema da lógica formal que trata das modalidades - isto é, à princípio, das possibilidades e das necessidades. Mortari (2001, p. 357) explica que "O adjetivo 'modal', à propósito, vem da expressão 'modos de verdade' [...]". Para expor de maneira breve, na interseção com a ideia de mundos possíveis, tudo o que é necessariamente verdadeiro deve ser verdadeiro em todos os mundos possíveis; tudo o que é possivelmente verdadeiro deve ser verdadeiro em pelo menos um mundo possível. Analisado sob essa ótica, Baudelaire cria uma outra visão para o evento histórico ao qual ele faz referência, produzindo um outro valor de verdade para o mesmo, em um outro mundo possível. Ele aproveita as ambiguidades existentes entre o factual e o ficcional para pensar as potências do falso na re-construção desse evento.

\section{CONCLUSÃO}

No contexto da arte contemporânea, a atual crise da noção de "verdade" permite que os três graus dos acontecimentos, já mencionados, coexistam em estratos e dialoguem entre si. A conhecida instalação de Pierre Huyghe, The Third Memory (2000), concretiza isso (Fig. 6), mostrando três registros de um determinado evento: o das grandes mídias e documentos de época, o do filme Um dia de cão (1975) e, por fim, o remake filmado pelo artista, quase trinta anos depois, com o assaltante do roubo a um banco que aconteceu em Nova lorque, em agosto de 1972 e que serviu de inspiração para o filme com Al Pacino.

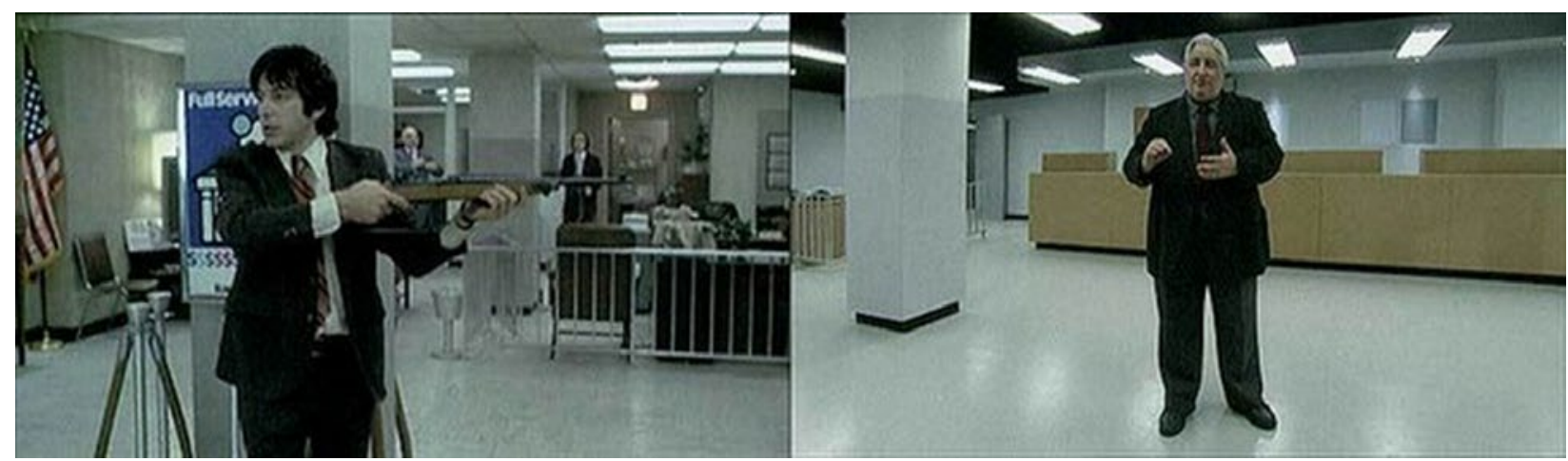

Fig. 6: Pierre Huyghe, The Third Memory, 2000. Filme, 10 minutos. Fonte: www.annasandersfilms.com/collection/pierre-huyghe/the-third-memoryl

Para explicar a questão dessa coexistência de versões gerada pela arte contemporânea, Éric Baudelaire (2018) convoca o paradoxo dos "futuros contingentes",

15 'Le fait qu'une observation attentive laisse percevoir qu'il s'agit d'une mise en scène place ce travail du côté d'une fiction critique, au prix cependant d'une certaine ambigüité."(DURAND, 2009, p. 32). 
uma questão filosófica que remonta à Antiguidade e que é de grande importância para o domínio da lógica, no qual as ditas teorias dos mundos possíveis se fundam. Baudelaire refere-se à obra de Gilles Deleuze, A imagem-tempo: cinema 2 (2005). Em um capítulo que, justamente, intitula-se As potências do falso, podemos ler

Se é verdade que uma batalha naval pode acontecer amanhã, como evitar uma das duas consequências seguintes: ou o impossivel procede do possível (já que, se a batalha acontece, não é mais possivel que ela não aconteça), ou o passado não é necessariamente verdadeiro (já que ela podia não acontecer). É fácil tratar tal paradoxo como sofisma. Mas ele não deixa de apontar a dificuldade que há em pensar uma relação direta da verdade com a forma do tempo, e nos condena a situar o verdadeiro longe do existente, no eterno ou no que imita o eterno. (DELEUZE, 2005, p. 160).

Segundo o filósofo, é com Leibniz, em seus Ensaios de Teodicéia (2017), que vemos a solução mais engenhosa para esse paradoxo, a partir do momento em que ele forja a noção de "incompossibilidade": "[...] Leibniz diz que a batalha naval pode acontecer ou não acontecer, mas que não é no mesmo mundo: ela acontece num mundo, não acontece em outro, e esses mundos são possíveis, mas não são 'compossíveis' entre si." (DELEUZE, 2005, p. 160). Assim, o incompossível - e não o impossível - se relaciona com o possível, permitindo que diferentes passados possam ser relatados sem ser necessariamente verdadeiros. De acordo com esse pensamento,

[...] as proposições que são verdadeiras não apenas no mundo real, mas também em todos os mundos possíveis, serão chamadas de verdades necessárias; reciprocamente, uma proposição é dita possível no mundo real, se ela for verdadeira em pelo menos um dos mundos possíveis acessíveis a partir do nosso. ${ }^{16}$ (PAVEL, 1988, p. 61, tradução nossa).

De acordo com a teoria dos mundos possíveis visuais, os diferentes mundos ditos incompossíveis podem habitar visualmente o espaço do mundo vivido, através de imagens. As artes visuais, dependendo da forma como a abordamos, têm o privilégio de ter como matéria-prima imagens que propagam o fazer mundo; imagens que fazem ato de autodenunciação e de simulação de outros mundos e outras versões do mundo dos fenômenos, da história e dos indivíduos. Nesse contexto, dentro desse campo, a fotografia encontra para si um lugar privilegiado, pois é um tipo de imagem técnica que tem credibilidade pelos seus fatores de reprodução e semelhança com o espaço do mundo vivido, encontrando uma eficácia comunicativa e afetiva. Assim, com facilidade, esse meio esbate as fronteiras dos fatos e das ficções, desloca vários limites e percorre os três graus dos acontecimentos.

Dessa forma, a atividade artística proporciona uma matéria sensível ao possível (CARVALHO, 2012), o que nos permite, enquanto espectadores, acessar esteticamente certos mundos possíveis através da imagem. Essa perspectiva abre terras férteis para se cultivar algo que nos motive enquanto sociedade, seja em termos de

16 "[...] les propositions qui sont vraies non seulement dans le monde réel, mais aussi dans tous les mondes possibles, seront appelées vérités nécessaires; réciproquement, une proposition est dite possible dans le monde réel, si elle est vraie dans au moins un des mondes possibles accessibles partir du nôtre." (PAVEL, 1988, p. 61). 
memória ou de futuro, sob uma ótica aiônica. Digo "terra" em três sentidos: a camada superficial do globo, elemento fértil onde plantar, fazer crescer, cultivar; o planeta Terra, dinâmico, mutável, planeta ameaçado; por fim, como área, território a ser implantado. Aceitar a natureza complexa e processual deste mundo dos fenômenos significa aceitar que outros mundos são também possíveis, em termos políticos, sociais, econômicos e ecológicos, e que a arte é catalisadora dessa marcha. O possível é processo, desestabilização e conclusão provisória. Mas é justamente essa instabilidade que permite uma motivação cheia de energia, que move, para poder prosseguir em tempos difíceis, algo que vejo como um caminho coletivo a ser percorrido com a ajuda da agentividade da imagem.

\section{REFERÊNCIAS BIBLIOGRÁFICAS}

BAQUÉ, D. Photographie plasticienne, l'extrême contemporain. Paris: Regard, 2004.

BAUDELAIRE, E. Potências do falso. Tradução: Lucas Eskinazi e Nina Guedes. ARS, São Paulo, v. 16, n. 33, p. 241-253, ago. 2018.

BAUDELAIRE, E. Eric Baudelaire by Benoît Rossel. BOMB Magazine, 15 jul. 2017. Disponível em: < https://bombmagazine.org/articles/eric-baudelaire/ >. Acesso em: 14 dez. 2020.

BELTING, H. La vraie image: croire aux images?. Paris: Gallimard, 2007.

BETHONICO, M. R. artista que fingere: a manipulação da imagem entre a imanência, as sobrevivências e a dupla-dobra. 2015. 141 p. Dissertação (Mestrado em Artes) - Escola de Belas Artes, Universidade Federal de Minas Gerais, Belo Horizonte, 2015. Disponível em: < https://repositorio.ufmg.br/handle/1843/EBAC-A47FYR >. Acesso em: 14 dez. 2020.

BETHONICO, M. R. IMAGE-FICTION, IMAGE-ACTION. Mise en jeu de la photographie contemporaine entre théorie des mondes possibles et théorie des actes d'image. 2019. 523 p. Tese (Doutorado em Artes) - Université Sorbonne Nouvelle Paris III, Paris, 2019. Disponível em: < https://tel.archives-ouvertes.fr/tel-02865326 >. Acesso em: 14 dez. 2020.

CARVAlHO, J. D. Artes e Mundos Possíveis. Aisthe, Rio de Janeiro, v. 6, n. 10, p. 120137, out. 2012.

CHÉROUX, C. Fautographie: petite histoire de l'erreur photographique. Crisnée: Yellow Now, 2003.

DELEUZE, G. A imagem-tempo: cinema 2. São Paulo: Brasiliense, 2005. 
DELEUZE, G. Logique du sens. Paris: Minuit, 1969.

DIDI-HUBERMAN, G. Ninfa moderna: essai sur le drapé tombé. Paris: Gallimard, 2002.

DUBOIS, P. De l'image-trace à l'image-fiction. Le mouvement des théories de la photographie de 1980 à nos jours. Études photographiques, Paris, n. 34, s.p., jun. 2016.

DURAND, R. L'impératif documentaire. In: Qu'est-ce que la photographie aujourd'hui ? Paris: Beaux-arts, 2009, p. 30-35.

GUNTHERT, A.; POIVERT, M. (org.). L'art de la photographie: des origines à nos jours. Paris: Citadelles \& Mazenod, 2007.

GUNTHERT, A. L'image partagée: la photographie numérique. Paris: Textuel, 2015.

GRENIER, C. La manipulation des images dans l'art contemporain: falsification, mythologisation, théâtralisation. Paris: Regard, 2014.

FINEMAN, M. Faking it: Manipulated Photography Before Photoshop. New York: Metropolitan Museum of Art, 2012.

LAVOCAT, F. Fait et fiction: pour une frontière. Paris: Seuil, 2016.

LEIBNIZ, G. W. Ensaios de Teodicéia sobre a bondade de Deus, a liberdade do homem e a origem do mal. São Paulo: Estação Liberdade, 2017.

MORTARI, C. A. Introdução à lógica. Sao Paulo: UNESP, 2001.

PAVEL, T. Univers de la fiction. Paris: Seuil, 1988.

POIVERT, M. La photographie contemporaine. Paris: Flammarion, 2002.

ROUILLÉ, A. La photographie: entre document et art contemporain. Paris: Gallimard, 2005. 